\title{
Ciliary Neurotrophic Factor Maintains Motoneurons and Their Target Muscles in Developing Rats
}

\author{
N. G. Forger, ${ }^{1}$ S. L. Roberts, ${ }^{1}$ V. Wong, ${ }^{3}$ and S. M. Breedlove ${ }^{1,2}$ \\ 'Department of Psychology and ${ }^{2}$ Graduate Group in Neurobiology, University of California, Berkeley, California 94720 and \\ ${ }^{3}$ Regeneron Pharmaceuticals, Tarrytown, New York, 10591
}

\begin{abstract}
Ciliary neurotrophic factor (CNTF) can enhance motoneuron survival during naturally occurring cell death in the chick (Oppenheim et al., 1991). Because receptors for CNTF are expressed in both motoneurons and their target muscles (Davis et al., 1991; Ip et al., 1993), both tissues are potential sites of CNTF action in development. We examined the ability of CNTF to prevent the degeneration of a neuromuscular system in developing female rats. The death of motoneurons in the spinal nucleus of the bulbocavernosus (SNB) extends postnatally and is sexually dimorphic, with many more motoneurons dying in females than in males. The bulbocavernosus (BC), a target muscle of SNB motoneurons, also degenerates postnatally in females. Female rats treated with daily injections of $1 \mu \mathrm{g}$ CNTF from embryonic day 22 through postnatal day 3 (P3) had $70 \%$ more SNB motoneurons on P4 than did control animals, and the number of pyknotic profiles in the SNB area was markedly reduced by CNTF. In addition, the degeneration of the $\mathrm{BC}$ was completely prevented by CNTF treatment of perinatal female rats. These results demonstrate that CNTF can preserve mammalian motoneurons from developmental death, but also suggest that the sparing effect of CNTF on motoneurons in vivo may be a secondary consequence of effects on target muscles.
\end{abstract}

[Key words: ciliary neurotrophic factor, neurotrophic factors, motoneurons, striated muscle, cell death]

About half of the motoneurons initially produced in rats degenerate during the normal course of development (Harris and McCaig, 1984; Oppenheim, 1986). Although signals from target muscles are thought to be important regulators of motoneuron death, the molecular mechanisms of cell survival remain unknown. Ciliary neurotrophic factor (CNTF) has recently gained attention as a potential motoneuronotrophic factor. CNTF bears no homology to the NGF family of neurotrophic molecules (Lin et al., 1989; Stöckli et al., 1989), but instead appears to be distantly related to a family of hematopoietic cytokines (Ip et al., 1992). Although originally isolated and molecularly cloned based on its ability to support parasympathetic neurons of the chick ciliary ganglion in vitro (Barbin et al., 1984), CNTF subsequently has been shown to enhance the short-term survival of embryonic chick and rat motoneurons in culture (Arakawa

\footnotetext{
Received Dec. 22, 1992; revised Apr. 20, 1993; accepted May 6, 1993.

We thank Paul Haller for photographic assistance. This work was supported by NIH Grant NS28421.

Correspondence should be addressed to Nancy $G$. Forger at the above address.

Copyright (c) 1993 Society for Neuroscience $0270-6474 / 93 / 134720-07 \$ 05.00 / 0$
}

et al., 1990; Magal et al., 1991). In addition, there are reports that the in vivo administration of CNTF spares about half of the spinal motoneurons that would otherwise die during the period of naturally occurring death in chicks (Oppenheim et al., 1991), prevents axotomy-induced death of facial motoneurons in rats (Sendtner et al., 1990), and spares facial motoneurons in a mousc mutant, progressive motor neuronopathy (Sendtner et al., 1992).

Testing the ability of CNTF to spare motoneurons during naturally occurring death poses a challenge in mammals, as the period of motoneuronal degeneration is exclusively prenatal for most mammalian motoneuron pools (Harris and McCaig, 1984; Oppenheim, 1986). The rat spinal nucleus of the bulbocavernosus (SNB) is exceptional, however, in that cell death in the SNB occurs primarily during the first postnatal week (Nordeen et al., 1985). SNB motoneurons reside in the ventromedial lumbar spinal cord and the majority of motoneurons in this nucleus innervate the bulbocavernosus (BC) and levator ani (LA), two sexually dimorphic, striated muscles active during copulation (Sachs, 1982; Wallach and Hart, 1983). Adult males have many more SNB motoneurons than do females (Breedlove and Arnold, 1980).

Previous studies have mapped the development of this sex difference in SNB motoneuron number (Nordeen et al., 1985; Sengelaub and Arnold, 1986). On embryonic day 18 (E18; day of birth = E23) the number of cells in the SNB is similar in males and females, but small relative to later values. Motoneuron number in the SNB increases over the next several days as cells migrate into the nucleus from a more lateral position in the spinal cord. This migration partly overlaps with the period of cell death, and motoneuron number in the SNB during the perinatal period can be understood as an interplay between the addition of cells by migration and elimination by cell death. The magnitude of motoneuron death in the SNB is androgen regulated and, as a result, males reach higher peak SNB cell numbers. Motoneuron number in the SNB declines only slightly between E22 and postnatal day 10 (P10) in males, while dropping markedly in females during the same interval. In addition, both the LA and BC target muscles were, until recently, thought to degenerate completely in normal females (Hayes, 1965; Cihak et al., 1970; Fishman and Breedlove, 1988), although there is now good evidence that a remnant LA persists (Tobin and Joubert, 1988; 1991). Perinatal androgen treatment of females prevents SNB motoneuron death and also promotes perineal muscle development (Breedlove and Arnold, 1983; Tobin and Joubcrt, 1991).

Thus, the SNB system of female rats presents a unique model 
of perinatal neuromuscular degeneration. Here we report that CNTF can overcome the usual requirement for androgen in the SNB system and can spare mammalian motoneurons from developmental cell death. Furthermore, we found that the CNTF treatment altered $\mathrm{BC}$ fate. In light of the observation that striated muscle abundantly expresses message for the CNTF $\alpha$-receptor (Davis et al., 1991), these results suggest that some of the effects of CNTF in vivo may be mediated via the target musculature.

\section{Materials and Methods}

Animal treatments. A large decline in SNB motoneuron number has been reported between E22 and P1 (Sengelaub et al., 1989). In order to begin CNTF treatments prior to this decline, timed-pregnant SpragueDawley rats were anesthetized by ether on E22 and their pups were delivered by cesarean section (day of sperm plug $=\mathrm{E} 1$ ). The dams were then overdosed with sodium pentobarbital without recovery from the anesthesia. One group of female pups was killed immediately and perfused through the heart with saline followed by buffered formalin (E22 group). The remaining females were anesthetized by hypothermia and $1 \mu \mathrm{g}$ of recombinant rat CNTF (Regeneron Pharmaceuticals) in a volume of $10 \mu \mathrm{l}$ or an equal volume of the vehicle (PBS containing $0.5 \mathrm{mg} / \mathrm{ml}$ BSA) was injected into the perineum on days E22, P1 (=E23), P2, and P3. The needle tip, visualized through the skin, was inserted about 1 $\mathrm{cm}$ from the midline and carefully positioned between the anus and clitoris, and the injection volume was deposited over the perineal muscles. Pups were warmed and returned to lactating foster dams. On P4, treated pups were overdosed with pentobarbital and perfused as above

Motoneuron measures. Lumbosacral spinal cords were removed and postfixed in formalin for at least 2 weeks, and then immersed in Bouin's solution for $24 \mathrm{hr}$ prior to paraffin cmbcdding. Scrial $12 \mu \mathrm{m}$ cross scctions were stained with thionin and bilateral counts were made of SNB motoneuronal nuclei in every section. Counts were adjusted for any torn or missing sections by interpolating the mean number of SNB motoneurons in neighboring sections. The soma, nucleus, and nucleolus of at least 20 cells from each animal were drawn by camera lucida and cross-sectional areas were determined by a digitizing pad linked to a microcomputer. The rostrocaudal extent of the SNB was determined by identifying the first and last sections in which at least one SNB motoneuron was counted. These and all other measurements were made by an observer blind to treatment group. Raw counts were corrected for split nuclei by the method of Konigsmark (1970), as motoneuronal nuclei closely conform to the assumptions of this counting method.

A separate count was made of all degenerating (pyknotic) cell profiles in the SNB arca of CNTF- and vehicle-treated animals. Pyknotic cells were recognized as described previously (Chu-Wang and Oppenheim, 1978; Forger and Breedlove, 1987) and counts were expressed per 100 sections counted to correct for any variation due to missing sections. The mean number of sections counted did not differ between groups $[\mathrm{CNTF}, 110 \pm 5$ sections ( $\pm \mathrm{SEM}$ ); vehicle, $108 \pm 5$ sections].

Determination of muscle volumes. A cube of tissue $(5-\mathrm{i} 0 \mathrm{~mm}$ on each side), including the entire perineal region, was cut out of 17 animals, immersed in Bouin's solution for $24-48 \mathrm{hr}$, and embedded in paraffin. Perineums were sectioned transverse to the rectum at a thickness of 8 $\mu \mathrm{m}$ and trichrome-stained to enhance the detection of muscle striations. Camera lucida tracings of the $\mathrm{LA}$ and $\mathrm{BC}$ were made from one of every 12 sections and muscle cross-sectional areas were determined on a digitizing pad. Approximate muscle volumes were then reconstructed by multiplying the total cross-scetional arca of cach musclc by the average distance between traced sections $(96 \mu \mathrm{m})$. Data on muscles and motoneurons were analyzed by one-way ANOVA, except where indicated. Post hoc comparisons were performed only following a significant $(p<$ 0.05) main effect.

\section{Results}

\section{Effects of CNTF on the SNB}

Daily CNTF treatment from E22 markedly increased SNB motoneuron number in female rats; animals treated with CNTF had $70 \%$ more SNB cells on P4 than did vehicle-treated controls (Fig. 1; $p<0.0001$ ). SNB cell number on E22 was intermediate, and significantly different from both the CNTF- and vehicletreated groups ( $p<0.05$ in both cases). The increase in SNB

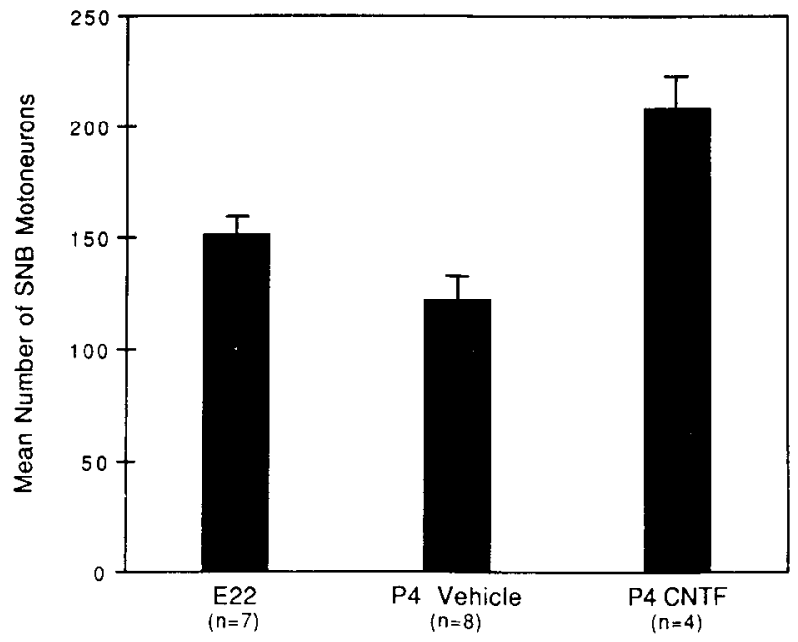

Figure 1. The number (mean \pm SEM) of SNB motoneurons in untreated females on E22 and in P4 females treated with daily injections of CNTF or vehicle alone from E22 to P3. CNTF significantly increased the number of SNB motoneurons surviving to $\mathrm{P} 4$.

motoneuron number in CNTF-treated animals may be attributed to a reduction in cell death, as the number of degenerating profiles in the SNB area of vehicle-treated animals was 3.2 times greater than that in animals receiving CNTF (Fig. $2 ; p<0.001$ ). CNTF treatment did not affect the cross-sectional area of SNB cell nuclei or nucleoli, nor was there an effect of CNTF treatment on the total rostrocaudal length of the SNB on P4 (Table 1). However, the mean cross-sectional area of SNB cell somata was slightly smaller in the CNTF-treated animals $(p<0.05$; Table 1).

Additional spinal cords were analyzed from pups treated exactly as described in Materials and Methods, except that the postfixation in Bouin's solution was omitted. Although material embedded directly out of formalin afforded superior differentiation of the thionin stain, it was difficult to section such cords without damage and neuronal counts were compromised. Nonetheless, blind counts were performed of live and pyknotic cells on cords of six CNTF- and four vehicle-treated animals embedded directly out of formalin. To distinguish effects of treatment from those induced by different fixatives, the data from all 22 animals killed on P4 were analyzed by two-way ANOVA with treatment and fixation as main effects. This analysis confirmcd all observations on Bouin's material described above, except that the effect of CNTF on soma size was not replicated in the material embedded out of formalin. Specifically, CNTF treatment resulted in significantly more SNB motoneurons ( $p$ $<0.0005)$ and fewer pyknotic profiles $(p<0.0001)$.

\section{The effect of CNTF on perineal muscles}

The LA of perinatal females was easily recognized as a thin strip of muscle looping around the rectum, as in males (Fig. 3). The histological morphology of the female $\mathrm{BC}$ has not previously been described. In males, the $\mathrm{BC}$ is divided into lateral and medial divisions, each of which attaches to and encircles the bulb of the penis (Hayes, 1965; McKenna and Nadelhaft, 1986). The proximal ends of the LA insert into the lateral BC and also attach to the base of the phallus (Hayes, 1965). In analogy with the morphology in males, we identified the $\mathrm{BC}$ in perinatal females as striated muscle fibers running horizontally betwecn the rectum and vagina that could sometimes be seen to contact 

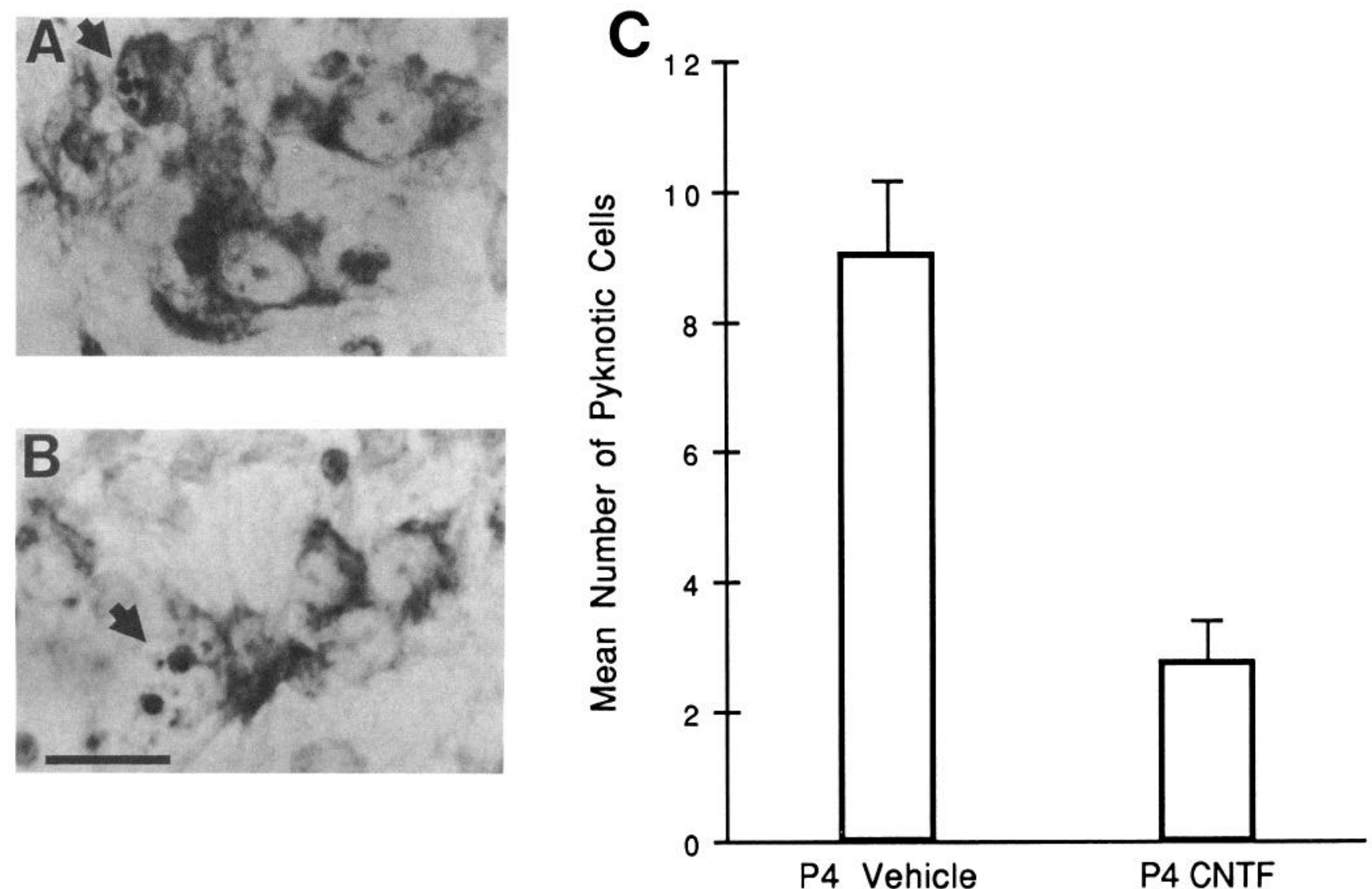

Figure 2. $A$ and $B$, Early- $(A)$ and late- $(B)$ phase degenerating cells (arrows) in the SNB region of control females on P4. Scale bar, $20 \mu \mathrm{m}$. $C$, The mean $( \pm$ SEM) number of pyknotic cells in vehicle- and CNTF-treated animals on P4. Pyknotic profiles were 3.2 times more abundant in control than in CNTF-treated animals.

the ends of the LA (Fig. 4). In addition, a thin strip of muscle fibers running in various orientations lateral to the vagina and urethra was present in some females and identified as $\mathrm{BC}$ (not shown). Some BC might also be expected dorsal to the urethra; however, fibers in this region were not drawn as we could not unambiguously distinguish $\mathrm{BC}$ from the ischiocavernosus muscle, which has similar attachments. The $\mathrm{BC}$ volumes reported here may therefore underestimate the full extent of this muscle.

Consistent with a report that the size of the female LA remains fairly constant during the neonatal period (Tobin and Joubert, 1991), there was no difference between the volume of the LA measured on E22 and that in vehicle-treated controls on P4 ( $p$ $>0.05$; Table 2 ). In contrast, LA volume was significantly greater in CNTF-treated females than in vehicle controls or E22 females ( $p<0.05$ in each case; Fig. 3, Table 2). The effect of $\mathrm{CNTF}$ was even more pronounced on the $\mathrm{BC}$, where muscle volume in CNTF-treated animals was 8.6 -fold greater than in vehicle controls ( $p<0.001$; Table 2$)$. Although the $\mathrm{BC}$ of females at E22 is already substantially smaller than in males (N. G. Forger, unpublished observations), BC was identified in all E22 animals and in all CNTF-treated animals on P4 (Fig. 4). In contrast, no BC fibers could be detected in four of the seven vehicle-treated controls. In the three controls in which some $\mathrm{BC}$ remained, BC volume was less than one-third that in CNTFtreated animals $\left(0.72 \pm 0.13\right.$ vs $2.67 \pm 0.12 \times \mathrm{mm}^{3} \times 10^{-2}$; $p<0.01)$ and was also significantly smaller than $\mathrm{BC}$ volumes observed at E22 (Table 2; $p<0.05$ ). These observations support the proposal by Cihak et al. (1970) that this muscle completely degenerates in untreated females. CNTF treatment not only prevented this degeneration but may in fact have stimulated muscle growth, as BC volume in CNTF-treated animals was significantly greater than at E22 $(p<0.05$; Table 2$)$.

Table 1. The effect of CNTF on SNB nucleus length and cell size

\begin{tabular}{lllll} 
& \multicolumn{3}{l}{ SNB cell size $\left(\mu \mathrm{m}^{2}\right)$} & \\
\cline { 3 - 5 } & Nucleus length $(\mathrm{mm})$ & Nucleoli & Nuclei & Somata \\
\hline Vehicle $(n=8)$ & $1.29 \pm 0.06$ & $3.13 \pm 0.21$ & $63.55 \pm 4.23$ & $135.77 \pm 6.82$ \\
CNTF $(n=4)$ & $1.36 \pm 0.12$ & $3.03 \pm 0.26$ & $61.25 \pm 8.51$ & $110.00 \pm 4.54^{*}$
\end{tabular}

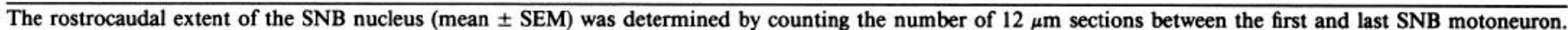

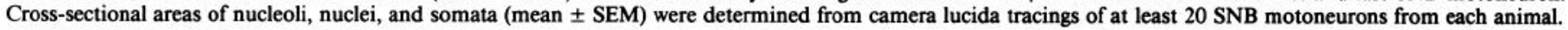
*Significantly different from vehicle-treated group, $p<0.05$. 
Body weight in CNTF-treated animals was not different from that in vehicle controls on $\mathrm{P} 4(p>0.05)$. Because the whole animal grows between E22 and P4, relative perineal muscle sizes were determined by correcting muscle volume for each individual's body weight $\left(\mathrm{mm}^{3} / \mathrm{gm}\right)$. The relative size of the LA was increased in CNTF-treated females on P4 compared to that at E22 $(p<0.05)$; however, the difference in BC size between these two groups did not reach statistical significance after correcting for body weight $(p=0.07)$.

\section{Discussion}

CNTF treatment from E22 to P3 completely prevented the decline in SNB motoneuron number that normally occurs in perinatal female rats. We conclude that CNTF is capable of saving mammalian motoneurons during developmental death, in confirmation of the results in embryonic chicks (Oppenheim et al., 1991). Although the number of SNB cells normally peaks at E22 (Nordeen et al., 1985), CNTF-treated females in this study actually had more SNB cells on P4 than did animals on E22. It is unlikely that an alteration of cell division contributed to the effect of CNTF on motoneuron number, since SNB motoneurons are all postmitotic by E14 (Breedlove et al., 1983) and our treatments did not begin until E22. The explanation for the increase in motoneuron number in CNTF-treated animals may reside in the fact that SNB motoneurons exhibit a period of secondary migration, from a more lateral position in the ventral spinal cord into the characteristic medial position of the SNB, which partly overlaps the period of CNTF treatment in this study (Sengelaub and Arnold, 1986). If CNTF treatment saved not only those cells already in the SNB on E22 but also new immigrants into the nucleus, a net gain in motoneuron number would be expected. Although we cannot rule out the possibility that CNTF treatment also altered migration into the SNB, a reduction in cell death clearly played a major role in maintaining SNB cell number, as evidenced by the large reduction in the number of degenerating cells in the SNB region of CNTF-treated animals.

In addition, atrophy of the perineal muscles was blocked in CNTF-treated females and, in fact, volumes of the BC and LA increased in animals treated with CNTF. This increased volume may be due to an increase in muscle fiber number and/or fiber size; however, assessment of muscle fiber number in neonatal rats will require analysis by electron microscopy (Ontell and Dunn, 1978). An action of CNTF on muscle as shown here has implications for the therapeutic use of CNTF in treating neuromuscular disorders and suggests a reassessment of CNTF as a purely "neuro"trophic factor (see also DiStefano et al., 1992).

Although males were not examined in the present study, the number of motoneurons in CNTF-treated females $(209 \pm 14)$ was somewhat lower than that previously reported for intact males or testosterone-treated females on P4 (approximately 260 motoneurons; Nordeen et al., 1985). Similarly, the size of the $\mathrm{BC}$ and LA target muscles in CNTF-treated females, although increased relative to control females, was nonetheless smaller than that in P4 males (not shown). This might be expected since motoneuron number and BC/LA size are already sexually dimorphic on E22, the day treatments were initiated in this study. It is possible that CNTF treatments begun before E22 would more completely reverse the sex difference. Similarly, androgen treatment from E16 through the neonatal period completely masculinizes SNB motoneuron number in females (Nordeen et al., 1985), whereas treatment begun on P1 does not (Breedlove and Arnold, 1983).
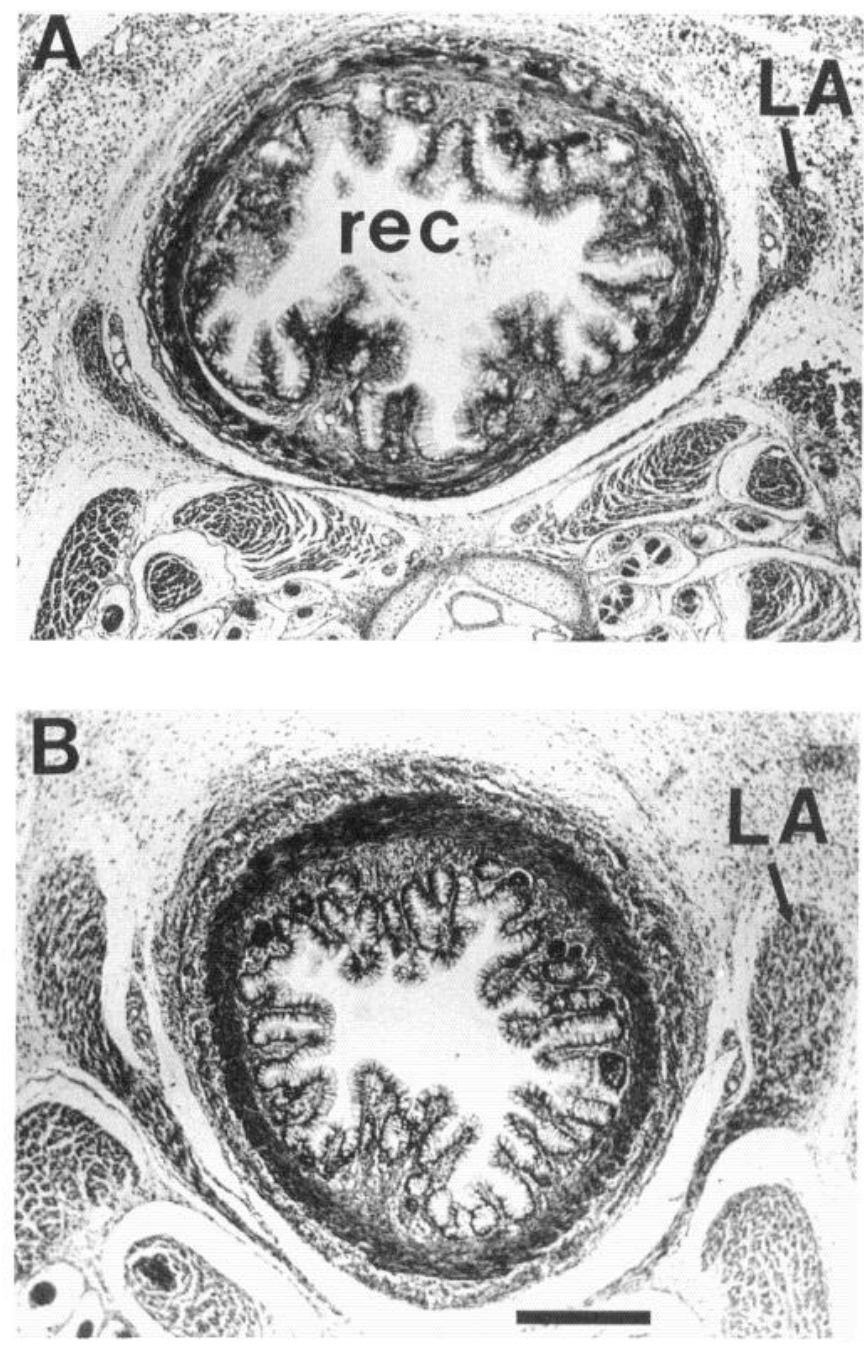

Figure 3. Cross sections through the perineum of female rats on P4. The LA can be seen looping around the rectum in these sections, taken approximately $1 \mathrm{~mm}$ from the opening of the anus. The LA was present in all animals, but smaller in vehicle controls $(A)$ than in females treated with $\mathrm{CNTF}(B)$. Dorsal is down. rec, rectum. Scale bar, $250 \mu \mathrm{m}$.

The mechanisms of action of CNTF are not yet clear. A direct effect on motoneurons is possible given the observations that CNTF promotes the short-term survival of purified chick motoneurons in vitro (Arakawa et al., 1990; Sendtner et al., 1991), and that CNTF receptors have been identified on motoneurons of neonatal rats by in situ hybridization (Ip et al., 1993). However, the marked effect on SNB target muscles suggests the possibility that in vivo CNTF may also act at target muscles to affect motoneuron survival indirectly. Indeed, CNTF has been reported to slow the atrophy of skeletal muscle following denervation (DiStefano et al., 1992; M. E. Helgren and P. S. DiStefano, unpublished observations). Atrophy of the perineal muscles appears to be the proximal cause of motoneuron degeneration in this system, as androgen spares SNB cells in developing rats at a time that the muscles (but not the motoneurons) are expressing androgen receptors (Fishman et al., 1990; Jordan et al., 1991), and can spare perineal muscles in the complete absence of innervation (Fishman and Breedlove, 1988). In analogy, CNTF may act at the BC/LA to induce the release of a second, motoneuronotrophic factor, or motoneuron survival may follow as some other consequence of CNTF's action on preserving the target muscles. Although such a mechanism 

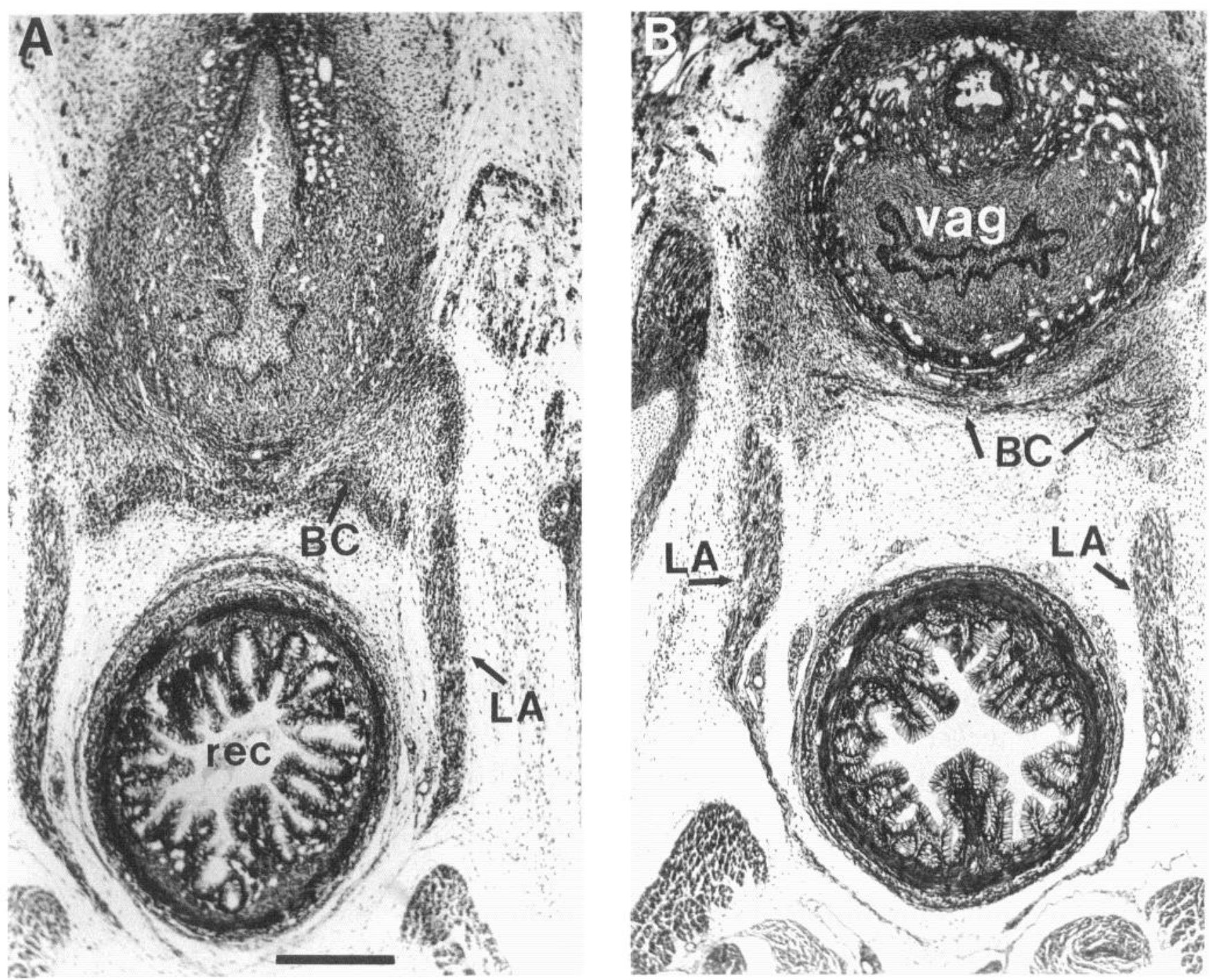

Figure 4. The LA and BC in an untreated female on E22 $(A)$ and a CNTF-treated female on P4 $(B)$. These sections are from a region of the perineum where the BC first becomes visible, approximately $300 \mu \mathrm{m}$ rostral to the views shown in Figure 3 . Little or no BC was found in vehicletreated controls on P4 (not shown). Dorsal is down. rec, rectum; vag, vagina. Scale bar, $250 \mu \mathrm{m}$.

is appealing in light of a large body of evidence that motoneuron survival is mediated by signals from target muscles (e.g., Hollyday and Hamburger, 1976), expression of CNTF receptors has not yet been assessed in the SNB-BC/LA system and our observations are also consistent with the possibility that CNTF acts at SNB motoneurons to promote muscle development in-

Table 2. Mean ( \pm SEM) volumes of the $\mathrm{LA}$ and $\mathrm{BC}$ in perinatal female rats on E22 and P4

\begin{tabular}{lll} 
& \multicolumn{2}{l}{ Muscle volume $\left(\mathrm{mm}^{3} \times 10^{-2}\right)$} \\
\cline { 2 - 3 } Treatment & LA & BC \\
\hline E22 $(n=4)$ & $4.46 \pm 1.12$ & $1.89 \pm 0.21$ \\
P4 vehicle $(n=7)$ & $4.70 \pm 0.41$ & $0.31 \pm 0.19^{*}$ \\
P4 CNTF $(n=6)$ & $8.46 \pm 1.49^{*} \dagger$ & $2.67 \pm 0.12^{*} \dagger$
\end{tabular}

Muscle volumes were reconstructed from camera lucida tracings of the $\mathrm{BC}$ and LA in $8 \mu \mathrm{m}$, trichrome-stained sections.

*Significantly different from E22, $p<0.05$.

†Significantly different from P4 vehicle, $p<0.05$. directly, or that both muscles and motoneurons respond independently. An analysis of the effects of CNTF on denervated perinatal BC may clarify this issue.

Regardless of its site(s) of action, exogenous CNTF clearly has potent effects on motoneuron survival. Whether it normally serves as a neurotrophic agent during ontogeny is unclear, in part because CNTF lacks the classical signal sequence of a secreted protein (Lin et al., 1989; Stöckli et al., 1989). However, unconventional modes of secretion have recently been described for a number of proteins, including interleukin-1 (Muesch et al., 1990; Rubartelli et al., 1990). In addition, a trophic factor for ciliary neurons, which shares approximately $50 \%$ amino acid identity with mammalian CNTF, has recently been cloned from embryonic chick eye (Leung et al., 1992). Although this molecule also lacks a signal sequence, it nonetheless appears to be secreted from transfected cells (Leung et al., 1992). A role for CNTF in development has also been questioned on the grounds that expression of CNTF could not be detected in embryonic or newborn rats (Stöckli et al., 1991). However, Ip et al. (1993) have recently reported CNTF expression as early as E11 in the rat, 
albeit at much lower levels than that seen in adult sciatic nerve (see also Altruda et al., 1992). This low level of CNTF expression, paired with expression of the CNTF $\alpha$-receptor in newborn rats (Ip et al., 1993), is consistent with a role for CNTF in normal mammalian development.

While both androgen and CNTF increase motoneuron survival in the SNB, it does not appear that CNTF prevents motoneuron death by an androgen-dependent mechanism. SNB soma size was smaller in CNTF-treated animals in one replication and unaffected in a second, results inconsistent with androgen's effect of increasing SNB soma size (Forger et al., 1992). The converse hypothesis, that sexual differentiation of SNB motoneuron number may normally involve androgenic regulation of the expression of CNTF or its receptors, warrants future study. Although purcly spcculative at this point, such a relationship would suggest that the regulation of neurotrophic molecules is one mechanism whereby steroids engender sex differences in neural structures.

\section{References}

Altruda F, Stefanuto G, Hirsch E, Silengo L, Collegaro L, Negro A (1992) Expression of human ciliary neurotrophic factor beta-galactosidase during development. Soc Neurosci Abstr 18:391.

Arakawa Y, Sendtner M, Thoenen HJ (1990) Survival effect of ciliary neurotrophic factor (CNTF) on chick embryonic motoneurons in culture: comparison with other neurotrophic factors and cytokines. J Neurosci 10:3507-3515.

Barbin G, Manthorpe M, Varon SJ (1984) Purification of the chick eye ciliary neuronotrophic factor. J Neurochem 43:1468-1478.

Breedlove SM, Arnold AP (1980) Hormone accumulation in a sexually dimorphic motor nucleus in the rat spinal cord. Science 210:564 566.

Breedlove SM, Arnold AP (1983) Hormonal control of a developing neuromuscular system. II. Sensitive periods for the androgen-induced masculinization of the rat spinal nucleus of the bulbocavernosus. $J$ Neurosci 3:424-432.

Breedlove SM, Jordan CL, Arnold AP (1983) Neurogenesis of motoneurons in the sexually dimorphic spinal nucleus of the bulbocavernosus in rats. Dev Brain Res 9:39-43.

Chu-Wang I-W, Oppenheim RW (1978) Cell death of motoneurons in the chick embryo spinal cord. I. A light and electron microscopic study of naturally occurring and induced cell loss during development. J Comp Neurol 177:33-58.

Cihak R, Gutmann E, Hanzlikova V (1970) Involution and hormoneinduced persistence of the $M$. sphincter (levator) ani in female rats. J Anat 106:93-110.

Davis S, Aldrich TH, Valenzuela DM, Wong V, Furth ME, Squinto SP, Yancopoulos GD (1991) The receptor for ciliary neurotrophic factor. Science 253:59-63.

DiStefano PS, Yancopoulos GD, Squinto SP (1992) Ciliary neurotrophic factor (CNTF) prevents denervation-induced atrophy of rat skeletal muscle. Neurology 42[Suppl 3]:336.

Fishman RB, Breedlove SM (1988) Neonatal androgen maintains sexually dimorphic muscles in the absence of innervation. Muscle Nerve 11:553-560.

Fishman RB, Chism L, Firestone GL, Breedlove SM (1990) Evidence for androgen receptors in sexually dimorphic perineal muscles of neonatal male rats. Absence of androgen accumulation by the perineal motoneurons. J Neurobiol 21:694-704.

Forger NG, Breedlove SM (1987) Motoneuronal death during human fetal development. J Comp Neurol 264:118-122.

Forger NG, Fishman RB, Breedlove SM (1992) Differential effects of testosterone metabolites upon the size of sexually dimorphic motoneurons in adulthood. Horm Behav 26:204-213.

Harris AJ, McCaig CD (1984) Motoneuron death and motor unit size during embryonic development of the rat. J Neurosci 4:13-24.

Hayes KJ (1965) The so-called 'levator ani' of the rat. Acta Endocrinol 48:337-347

Hollyday M, Hamburger V (1976) Reduction of the naturally occur- ring motor neuron loss by enlargement of the periphery. J Comp Neurol 170:311-320.

Ip NY, Nye SH, Boulton TG, Davis S, Taga T, Li Y, Birren SJ, Yasukawa K, Kishimoto T, Anderson DJ, Stahl N, Yancopoulos D (1992) CNTF and LIF act on neuronal cells via shared signaling pathways that involve the IL-6 signal transducing receptor component gp130. Cell 69:1121-1132.

Ip NY, McClain J, Barrezueta NX, Aldrich TH, Pan L, Li Y, Weigand SJ, Friedman B, Davis S, Yancopoulos GD (1993) The alpha component of the CNTF receptor is required for signaling and defines potential CNTF targets in the adult and during development. Neuron 10:89-102

Jordan CL, Breedlove SM, Arnold AP (1991) Ontogeny of steroid accumulation in spinal lumbar motoneurons of the rat: implications for androgen's site of action during synapse elimination. J Comp Neurol 312:1-8.

Konigsmark BW (1970) Methods for the counting of neurons. In: Contemporary research methods in neuroanatomy (Nauta WJH, Ebbesson SOE, eds), pp 315-340. New York: Springer.

Leung DW, Parent AS, Cachianes G, Esch F, Coulombe JN, Nikolics K, Eckenstein FP, Nishi R (1992) Cloning, expression during development, and evidence for release of a trophic factor for ciliary ganglion neurons. Neuron 8:1045-1053.

Lin L-FH, Mismer D, Lile JD, Armes LG, Butler ET, Vannice JL, Collins F (1989) Purification, cloning, and expression of ciliary neurotrophic factor (CNTF). Science 246:1023-1025.

Magal E, Burnham P, Varon S (1991) Effects of ciliary neuronotrophic factor on rat spinal cord neurons in vitro: survival and expression of choline acetyltransferase and low-affinity nerve growth factor receptors. Dev Brain Res 63:141-150.

McKenna KE, Nadelhaft I (1986) The organization of the pudendal nerve in the male and female rat. J Comp Neurol 248:532-549.

Muesch A, Hartmann E, Rohde K, Rubartelli A, Sitia R, Rapoport TA (1990) A novel pathway for secretory proteins? Trends Biochem Sci 15:86-88.

Nordeen EJ, Nordeen KW, Sengelaub DR, Arnold AP (1985) Androgens prevent normally occurring cell death in a sexually dimorphic spinal nucleus. Science 229:671-673.

Ontell M, Dunn RF (1978) Neonatal muscle growth: a quantitative study. Am J Anat 152:539-556.

Oppenheim RW (1986) The absence of significant postnatal motoneuron death in the brachial and lumber spinal cord of the rat. $J$ Comp Neurol 246:281-286.

Oppenheim R, Prevette D, Qin-Wei Y, Collins F, MacDonald J (1991) Control of embryonic motoneuron survival in vivo by ciliary neurotrophic factor. Science 251:1616-1618.

Rubartelli A, Cozzolino F, Talio M, Sitia R (1990) A novel secretory pathway for interleukin- $1 \beta$, a protein lacking a signal sequence. EMBO J 9:1503-1510.

Sachs BD (1982) Role of the rat's striated penile muscles in penile reflexes, copulation and the induction of pregnancy. J Reprod Fertil $66: 433-443$

Sendtner M, Kreutzberg GW, Thoenen H (1990) Ciliary neurotrophic factor prevents the degeneration of motor neurons after axotomy. Nature 345:440-441.

Sendtner M, Arakawa Y, Stöckli KA, Kreutzberg G, Thoenen H (1991) Effect of ciliary neurotrophic factor (CNTF) on motoneuron survival. J Cell Sci [Suppl] 15:103-109.

Sendtner M, Schmalbruch H, Stöckli KA, Carroll P, Kreutzberg GW, Thoencn H (1992) Ciliary neurotrophic factor prevents degeneration of motor neurons in mouse mutant progressive motor neuronopathy. Nature 358:502-504.

Sengelaub DR, Arnold AP (1986) Development and loss of early projections in a sexually dimorphic rat spinal nucleus. J Neurosci 6:1613-1620.

Sengelaub DR, Jordan CL, Kurz EM, Arnold AP (1989) Hormonal control of neuron number in sexually dimorphic spinal nuclei of the rat: I. Testosterone-regulated death in the dorsolateral nucleus. J Comp Neurol 280:622-629.

Stöckli KA, Lottspeich F, Sendtner M, Masiakowski P, Carroll P, Gotz R, Lindholm D, Thoenen H (1989) Molecular cloning, expression and regional distribution of rat ciliary neurotrophic factor. Nature 342:920-922.

Stöckli KA, Lillien LE, Naher-Noe M, Breitfeld G, Hughes RA, Raff 
MC, Thoenen H, Sendtner M (1991) Regional distribution, developmental changes, and cellular localization of CNTF-mRNA and protein in the rat brain. J Cell Biol 115:447-459.

Tobin C, Joubert Y (1988) The levator ani of the female rat: a suitable model for studying the effects of testosterone on the development of mammalian muscles. Biol Struct Morphogen 1:28-33.
Tobin C, Joubert Y (1991) Testosterone-induced development of the rat levator ani muscle. Dev Biol 146:131-138.

Wallach SJR, Hart BJ (1983) The role of the striated penile muscles of the male rat in seminal plug dislodgement and deposition. Physiol Behav 31:815-821. 